\title{
Evaluasi Proses Manajemen Logistik Obat di UPTD Puskesmas Kabupaten Sampang
}

\section{Evaluation of the Drug Logistics Management Process at the UPTD Sampang District Public Health Center}

\author{
Ana Mariatul Ulfa*1, Djazuly Chalidyanto ${ }^{1}$
}

\begin{abstract}
ABSTRAK
Latar Belakang: Data Laporan Pemakaian dan Lembar Permintaan Obat (LPLPO) di Kabupaten Sampang menunjukkan bahwa seluruh puskesmas di Kabupaten Sampang mengalami stagnant obat dengan rata-rata sebanyak 43\% di seluruh puskesmas pada bulan Januari sampai bulan Oktober tahun 2019.

Tujuan: Tujuan penelitian ini adalah menganalisis proses manajemen logistik obat di puskesmas di Kabupaten Sampang dan melihat kesesuaiannya dengan Peraturan Menteri Kesehatan Nomor 74 Tahun 2016.

Metode: Penelitian ini berjenis observasional dengan rancang bangun cross sectional. Penelitian ini dilakukan pada Juli 2020 dengan metode wawancara, observasi, dan studi dokumen. Sampel dipilih menggunakan metode purposive sampling yaitu sebanyak sepuluh puskesmas yang terdiri atas lima puskesmas dengan angka stagnant tinggi dan lima lainnya rendah. Keseluruhan proses manajemen logistik obat di puskesmas akan dibandingkan dengan Peraturan Menteri Kesehatan Nomor 74 Tahun 2016 untuk dilihat kesesuaiannya.

Hasil: Hasil dari penelitian ini menunjukkan bahwa pada proses pencatatan, pelaporan, dan pengarsipan obat 20\% puskesmas dengan angka stagnant tinggi belum sesuai dengan Peraturan Menteri Kesehatan Nomor 74 Tahun 2016. Selanjutnya, pada proses pemantauan dan evaluasi seluruh puskesmas baik puskesmas dengan angka stagnant tinggi maupun puskesmas dengan angka stagnant rendah belum sesuai dengan Peraturan Menteri Kesehatan Nomor 74 Tahun 2016.

Kesimpulan: Terdapat dua proses yang belum sesuai dengan Peraturan Menteri Kesehatan Nomor 74 Tahun 2016 yaitu proses pencatatan, pelaporan, dan pengarsipan obat serta proses pemantauan dan evaluasi obat. Oleh karena itu, perlu dilakukan monitoring dan evaluasi manajemen logistik secara berkala agar dapat dilakukan tindakan segera apabila terdapat hal yang tidak sesuai dengan rencana awal.
\end{abstract}

Kata kunci : evaluasi, manajemen logistik, obat, puskesmas

\begin{abstract}
Background: Data of The Usage Report and The Demand Sheet of Drugs in Sampang District showed that all public health center in Sampang District experienced drug stagnant with an average of $43 \%$ in all public health center from January to October 2019.

Objectives: The purpose of this study was to analyze the process of drug management at the public health center in Sampang District and its appropriate with the Minister of Health Regulation Number 74 in the year 2016.

Methods: The research type was observational with a cross-sectional design. The research was conducted in July 2020 using interview, observation, and document study methods. The sample was took ten public health centers, of which five public health center with high numbers stagnant and five others are low. The sample was taken through the purposive sampling technique. The entire drug logistics management process at the public health center will be compared with the Minister of Health Regulation Number 74 in the year 2016.

Results: The results of this study indicate that in the drugs recording, reporting, and filing at 20\% public health centers with high stagnant numbers are not following the Minister of Health Regulation Number 74 in the year 2016. Furthermore, in the drugs monitoring and evaluation process, both public health centers with high stagnant numbers and low stagnant numbers are not following the Minister of Health Regulation Number 74 in the year 2016.
\end{abstract}


Conclusions: Two processes are not following the Minister of Health Regulation Number 74 in the year 2016. The logistic management process is not yet under the regulation, namely the drugs recording, reporting, and filling process and drugs monitoring and evaluating process. Therefore, it is necessary to monitor and evaluate logistics management regularly. So, immediate action can be taken if something is not under the original plan.

Keywords: evaluation, logistic management, drugs, public health center

\author{
*Koresponden: \\ ana.mariatul.ulfa-2016@fkm.unair.ac.id; \\ Ana Mariatul Ulfa \\ ${ }^{1}$ Departemen Administrasi dan Kebijakan Kesehatan, Fakultas Kesehatan Masyarakat, Universitas Airlangga \\ Kampus C Mulyorejo, 60115, Surabaya, Jawa Timur, Indonesia
}

\title{
PENDAHULUAN
}

Laporan Direktorat Pelayanan Kefarmasian Tahun 2018 menyebutkan bahwa persentase puskesmas yang melakukan pelayanan kefarmasian sesuai dengan standar pada Tahun 2018 sebesar 55,13\% dari keseluruhan puskesmas yang ada (Kementrian Kesehatan Republik Indonesia, 2019). Selanjutnya, dalam Laporan Direktorat Pelayanan Kefarmasian Tahun 2019 disebutkan bahwa persentase puskesmas yang melakukan pelayanan kefarmasian sesuai dengan standar pada tahun 2019 sebesar 60,06\%. Berdasarkan laporan tersebut diketahui bahwa hampir setengah dari keseluruhan puskesmas secara nasional belum melakukan pelayanan kefarmasian sesuai dengan standar. Dalam laporan kinerja Direktorat Pelayanan Kefarmasian tahun 2019 juga disebutkan bahwa beberapa permasalahan terkait ketidaksesuaian pelayanan kefarmasian di puskesmas dengan standar antara lain belum semua puskesmas memiliki tenaga kefarmasian khususnya apoteker untuk melaksanakan pelayanan kefarmasian sesuai standar, tenaga apoteker dan tenaga kefarmasian di puskesmas jarang/tidak pernah mendapatkan pelatihan pelayanan kefarmasian, dan belum semua puskesmas melaporkan pelayanan kefarmasian mereka (Kementrian Kesehatan Republik Indonesia, 2020).

Permasalahan terkait obat dapat berasal dari beberapa komponen yang berhubungan dengan manajemen logistik obat. Seperti perencanaan obat, penerimaan obat pendistribusian obat, penyimpanan obat, dan proses lainnya. Adanya perbedaan kondisi wilayah dan pola penyakit antardaerah dapat menjadikan kebutuhan obat berbeda-beda antardaerah. Oleh sebab itu puskesmas dan Dinas Kesehatan harus membuat rencana kebutuhan obat dengan tepat dan akurat (Sardjoko et al., 2018).

Selain karena perbedaan kondisi wilayah dan pola penyakit antardaerah, hal lain yang berpengaruh yaitu sumber daya manusia yang ada di puskesmas. Adanya Keterbatasan tenaga apoteker atau farmasi di setiap puskesmas bisa mempengaruhi proses perencanaan obat. Perencanaan obat dapat tidak akurat jika tidak melihat data tren dan memperhatikan kebutuhan atau pola penyakit di daerah. Selain itu, sedikitnya pelatihan dan peningkatan kapasitas sumber daya manusia di puskesmas juga dapat berpengaruh. Selain aspek perencanaan, manajemen logitik obat di puskesmas juga harus diperkuat (Sardjoko et al., 2018).

Akibat dari perencanaan obat yang tidak tepat dan manajemen logistik obat yang lemah dapat menyumbang pada terjadinya kekurangan atau kekosongan obat di puskesmas, selain juga dipengaruhi oleh pengiriman obat oleh supplier. Selain kekurangan atau kekosongan obat, di puskesmas juga terjadi penumpukan obat program dalam jumlah besar. Hal ini menyebabkan banyak obat program yang tidak bisa digunakan dan menjadi kedaluwarsa (Sardjoko et al., 2018).

Permasalahan terkait kekosongan atau kekurangan obat serta terjadinya penumpukan obat berhubungan erat dengan manajemen logistic obat. Oleh karena itu penting untuk menjalankan seluruh proses manajemen logistik obat yang sesuai dengan standar. Menurut penelitian (Abadi, 2015) stok obat yang berlebih (stagnant) bisa mengakibatkan obat menjadi kedaluwarsa dan menimbulkan kerugian material.

Berdasarkan data Laporan Pemakaian dan Lembar Permintaan Obat (LPLPO) puskesmas Kabupaten Sampang diketahui bahwa seluruh puskesmas di Kabupaten Sampang mengalami stagnant obat dengan angka yang beragam. Hal ini dapat terjadi karena adanya masalah pada manajemen pengelolaan obat di puskesmas. Masalah yang terjadi adalah tingginya kejadian stagnant obat dengan rata-rata $43 \%$ dari seluruh puskesmas di UPTD puskesmas Kabupaten Sampang pada bulan Januari sampai bulan Oktober tahun 2019 (Dinas Kesehatan Kabupaten Sampang, 2019).

Karena tingginya angka stagtant obat tersebut akhirnya tujuan penelitian ini yaitu untuk menganalisis proses manajemen logistik obat di puskesmas dan melihat kesesuaiannya dengan Peraturan Menteri Kesehatan Nomor 74 Tahun 2016 tentang Standar Pelayanan Kefarmasian di puskesmas. Manfaat penelitian ini yaitu sebagai bahan masukan untuk perbaikan kondisi manajemen logistik obat di puskesmas. 


\section{METODE}

Penelitian ini termasuk penelitian deskriptif observasional. Bersifat observasional dimana dalam pengumpulan data tidak ada intervensi pada subjek penelitian. Penelitian ini bersifat deskriptif yaitu untuk menggambarkan suatu fenomena yang ditemukan. Penelitian ini bertujuan untuk memperoleh gambaran dan menganalisis proses manajemen logistik obat di puskesmas dan melihat kesesuaiannya dengan Peraturan Menteri Kesehatan Nomor 74 Tahun 2016. Teknik pengumpulan data dilakukan dengan wawancara, observasi, dan studi dokumen. Populasi pada penelitian ini adalah UPTD puskesmas Kabupaten Sampang yang berjumlah 21 puskesmas. Cara penentuan sampel yaitu dengan menggunakan teknik purposive sampling dan dipilih sebanyak sepuluh puskesmas. Puskesmas yang dipilih adalah lima puskesmas dengan persentase stagnant obat tinggi serta lima puskesmas dengan persentase stagnant obat rendah. Data yang terkumpul akan dianalisis dengan analisis deskriptif yaitu berupa narasi yang berisi analisis proses manajemen logistik obat di puskesmas dan kesesuaiannya dengan Peraturan Menteri Kesehatan No 74 tahun 2016. Proses manajemen yang dianalisis antara lain perencanaan obat, permintaan obat, penerimaan obat, penyimpanan obat, pendistribusian obat, pencatatan, pelaporan, dan pengarsipan obat, serta pemantauan dan evaluasi obat.

\section{HASIL DAN PEMBAHASAN}

\section{Kesesuaian Proses Manajemen Logistik Obat di Puskesmas dengan Peraturan Menteri Kesehatan Nomor 74 Tahun 2016}

Pada Tabel 1 dapat diketahui bahwa dari keseluruhan proses manajemen logistik, tidak ada perbedaan antara puskesmas dengan angka stagnant tinggi maupun puskesmas dengan angka stagnant rendah terkait proses perencanaan, permintaan, penerimaan, penyimpanan, dan pendistribusian obat. Selanjutnya, pada proses pencatatan, pelaporan, dan pengarsipan obat, terdapat perbedaan di mana pada puskesmas dengan angka stagnant rendah seluruh puskesmas telah sesuai dengan Peraturan Menteri Kesehatan Nomor 74 Tahun 2016 , sedangkan pada puskesmas dengan angka stagnant tinggi $80 \%$ telah sesuai dengan Peraturan Menteri Kesehatan Nomor 74 Tahun 2016. Kemudian terkait proses pemantauan dan evaluasi obat, seluruh puskesmas belum sesuai dengan Peraturan Menteri Kesehatan Nomor 74 Tahun 2016.

Tabel 1. Rekapitulasi Kesesuaian Proses Manajemen Logistik Obat di Puskesmas dengan Peraturan Menteri Kesehatan Nomor 74 Tahun 2016

\begin{tabular}{|c|c|c|c|c|c|c|c|}
\hline \multirow{3}{*}{ Proses Manajemen Logistik } & \multirow{3}{*}{ Kategori Puskesmas } & \multicolumn{6}{|c|}{$\begin{array}{l}\text { Kesesuaian dengan Permenkes No. } 74 \text { Tahun } \\
2016\end{array}$} \\
\hline & & \multicolumn{2}{|c|}{ Sesuai } & \multicolumn{2}{|c|}{ Tidak Sesuai } & \multicolumn{2}{|c|}{ Jumlah } \\
\hline & & $\mathrm{n}$ & $\%$ & $\mathrm{n}$ & $\%$ & $\mathrm{n}$ & $\%$ \\
\hline \multirow[t]{2}{*}{ 1. Perencanaan } & Stagnant Tinggi & 5 & 100 & 0 & 0 & 5 & 100 \\
\hline & Stagnant Rendah & 5 & 100 & 0 & 0 & 5 & 100 \\
\hline \multirow{2}{*}{ 2. Permintaan } & Stagnant Tinggi & 5 & 100 & 0 & 0 & 5 & 100 \\
\hline & Stagnant Rendah & 5 & 100 & 0 & 0 & 5 & 100 \\
\hline \multirow{2}{*}{ 3. Penerimaan } & Stagnant Tinggi & 5 & 100 & 0 & 0 & 5 & 100 \\
\hline & Stagnant Rendah & 5 & 100 & 0 & 0 & 5 & 100 \\
\hline \multirow[t]{2}{*}{ 4. Penyimpanan } & Stagnant Tinggi & 5 & 100 & 0 & 0 & 5 & 100 \\
\hline & Stagnant Rendah & 5 & 100 & 0 & 0 & 5 & 100 \\
\hline \multirow[t]{2}{*}{ 5. Pendistribusian } & Stagnant Tinggi & 5 & 100 & 0 & 0 & 5 & 100 \\
\hline & Stagnant Rendah & 5 & 100 & 0 & 0 & 5 & 100 \\
\hline \multirow[t]{2}{*}{$\begin{array}{l}\text { 6. Pencatatan, Pelaporan, } \\
\text { dan Pengarsipan }\end{array}$} & Stagnant Tinggi & 4 & 80 & 1 & 20 & 5 & 100 \\
\hline & Stagnant Rendah & 5 & 100 & 0 & 0 & 5 & 100 \\
\hline \multirow{2}{*}{$\begin{array}{l}\text { 7. Pemantauan dan } \\
\text { Evaluasi }\end{array}$} & Stagnant Tinggi & 0 & 0 & 5 & 100 & 5 & 100 \\
\hline & Stagnant Rendah & 0 & 0 & 5 & 100 & 5 & 100 \\
\hline
\end{tabular}




\section{Proses Perencanaan Obat}

Pada penelitian ini diketahui bahwa proses perencanaan telah sesuai dengan Peraturan Menteri Kesehatan Nomor 74 Tahun 2016, baik pada di di puskesmas dengan angka stagnant tinggi maupun pada puskesmas dengan angka stagnant rendah. Terdapat empat indikator yang dilihat dalam proses perencanaan obat yang disesuaikan dengan Peraturan Menteri Kesehatan Nomor 74 Tahun 2016 yang terdiri dari pertimbangan proses seleksi, kesesuaian dengan Formularium Nasional (Fornas) dan Daftar Obat Esensial Nasiona; (DOEN), keterlibatan tenaga kesehatan lain, dan frekuensi perencanaan obat (Kementerian Kesehatan Republik Indonesia, 2016).

Pada penelitian ini diketahui bahwa terkait pertimbangan proses seleksi obat, 2 puskesmas (40\%) dengan angka stagnant tinggi belum sesuai dengan Peraturan Menteri Kesehatan Nomor 74 Tahun 2016, sedangkan pada puskesmas dengan angka stagnant rendah seluruh puskesmas telah sesuai dengan Peraturan Menteri Kesehatan Nomor 74 Tahun 2016. Berdasarkan hasil wawancara diketahui bahwa seluruh puskesmas menggunakan metode pola konsumsi obat dan melihat data sediaan farmasi pada periode sebelumnya pada proses perencanaan obat. Informan juga mengatakan bahwa angka konsumsi obat dan data sediaan farmasi dapat dilihat pada LPLPO. Beberapa puskesmas juga mempertimbangkan pola penyakit di wilayah kerjanya pada proses perencanaan obat. Jika mengacu pada Peraturan Menteri Kesehatan Nomor 74 Tahun 2016 maka semakin banyak pertimbangan yang dilakukan pada proses seleksi obat akan semakin baik pula hasil perencanaan obat yang dilakukan.

Selain itu juga diketahui bahwa seluruh puskesmas baik puskesmas dengan angka stagnant tinggi maupun puskesmas dengan angka stagnant rendah telah mengacu pada Fornas dan DOEN untuk proses seleksi obat. Sedangkan untuk keterlibatan tenaga kesehatan lain pada proses seleksi obat terdapat 1 puskesmas (20\%) dengan angka stagnant tinggi belum melibatkan lebih dari dua tenaga kesehatan pada proses perencanaan obat. Sedangkan pada puskesmas dengan angka stagnant rendah seluruh puskesmas telah melibatkan lebih dari dua tenaga kesehatan pada proses perencanaan obat.

Menurut Nopiyansyah et al., (2020) kurangnya perencanaan bisa mengakibatkan terjadinya kekosongan obat. Salah satu masalah pada perencanaan obat adalah hanya mempertimbangkan metode konsumsi dan kurang memperhatikan pola penyakit, sehingga stok obat menjadi tidak pasti. Perencanaan kebutuhan obat yang tidak maksimal dapat menyebabkan obat mengalami stock out (Erlin, 2017). Selain metode konsumsi, pertimbangan lainnya yaitu pola penyakit di wilayah kerja puskesmas. Perencanaan obat juga sebaiknya melihat pola penyakit, karakteristik pasien (jenis kelamin, umur, dan lain-lain), stok di puskesmas, dan pemakaian rata-rata setiap bulannya. Hal ini agar perencanaan menjadi tepat jenis dan tepat jumlah (Nurniati dan Lestari, 2017).

\section{Proses Permintaan Obat}

Pada penelitian ini, diketahui bahwa proses permintaan obat telah sesuai dengan Peraturan Menteri Kesehatan Nomor 74 Tahun 2016, baik pada puskesmas dengan angka stagnant tinggi maupun pada puskesmas dengan angka stagnant rendah. Terdapat dua indikator yang dilihat dalam proses permintaan obat yang disesuaikan dengan Peraturan Menteri Kesehatan Nomor 74 Tahun 2016 yang terdiri mengirimkan form LPLPO dan ketepatan waktu pengiriman form LPLPO (Kementerian Kesehatan Republik Indonesia, 2016).

Selanjutnya dari hasil wawancara diketahui bahwa permintaan obat dilakukan oleh puskesmas dengan mengirimkan form LPLPO setiap bulan kepada Instalasi Farmasi Kabupaten (IFK). Seluruh puskesmas baik puskesmas dengan angka stagnant tinggi maupun puskesmas dengan angka stagnant rendah telah mengirimkan form LPLPO kepada IFK setiap bulannya. Terkait ketepatan waktu pengiriman LPLPO terdapat 2 puskesmas (40\%) dengan angka stagnant tinggi belum mengirimkan form LPLPO dengan tepat waktu, selanjutnya sebanyak 1 puskesmas (20\%) dengan angka stagnant rendah juga belum mengirimkan form LPLPO tepat waktu kepada IFK. Berdasarkan hasil wawancara yang dilakukan diketahui bahwa batas waktu pengiriman LPLPO yang ditentukan oleh IFK adalah tanggal 5 pada awal bulan.

LPLPO mempunyai fungsi yang kompleks. LPLPO yang dibuat oleh puskesmas harus tepat isi, tepat data, dikirim tepat waktu ke IFK dan diarsipkan dengan baik. Apabilan pengiriman LPLPO dari puskesmas terlambah makan akan memengaruhi pengelolaan obat di IFK (Soeprijanto, Hapsari dan Utaminingrum, 2016). Selain itu ketidaktepatan pengiriman LPLPO juga memengaruhi proses pembentukan informasi di IFK. Penelitian yang dilakukan oleh (Waluyo, Athiyah dan Nurul Rochmah, 2014) diketahui bahwa keterlambatan pengiriman LPLPO di puskesmas tempat dia meneliti disebabkan oleh tidak ada atau sulitnya akses pengiriman. Selain itu LPLPO harus dibawa oleh petugas puskesmas sendiri karena tidak ada petugas khusus seperti asisten apoteker di puskesmas untuk membantu membuat LPLPO. Di samping itu karena kurangnya SDM menyebabkan petugas harus bertanggungjawab atas beberapa pekerjaan. 


\section{Proses Penerimaan Obat}

Pada penelitian ini, diketahui bahwa proses penerimaan obat telah sesuai dengan Peraturan Menteri Kesehatan Nomor 74 Tahun 2016, baik pada puskesmas dengan angka stagnant tinggi maupun pada puskesmas dengan angka stagnant rendah. Terdapat enam indikator yang dilihat dalam proses penerimaan obat yang disesuaikan dengan Peraturan Menteri Kesehatan Nomor 74 Tahun 2016 terdiri pengecekan dokumen, jumlah kemasan/peti, jenis obat, bentuk obat, jumlah obat, dan tanggal kedaluwarsa (Kementerian Kesehatan Republik Indonesia, 2016).

Selanjutnya dari hasil wawancara diketahui bahwa masih terdapat puskesmas yang belum melakukan pengecekan terhadap jenis dan bentuk obat pada saat penerimaan obat. Hanya 1 puskesmas (20\%) dengan angka stagnant tinggi maupun puskesmas dengan angka stagnant rendah yang melakukan pengecekan terhadap jenis obat pada proses penerimaan. Selanjutnya, hanya terdapat 1 puskesmas (20\%) dari puskesmas dengan angka stagant rendah yang melakukan pengecekan terhadap bentuk obat pada proses penerimaan. Berdasarkan hasil wawancara yang dilakukan, diketahui bahwa pengecekan pada saat penerimaan obat pada sebagian besar puskesmas hanya melihat pada apa yang tertera di Surat Bukti Pengeluaran Barang yang diberikan oleh IFK saat mendistribusikan obat ke puskesmas. Pada surat tersebut hanya terdapat satuan, nomor batch, tanggal kedaluwarsa obat, dan jumlah obat. Sebagian besar puskesmas hanya memeriksa jumlah dan tanggal kedaluwarsa dari obat yang datang.

Petugas yang melakukan penerimaan obat harus melakukan pemeriksaan fisik, penyimpanan obat, pemindahan, serta pemeliharaan obat termasuk menjaga kelengkapan catatan yang menyertainya. Petugas juga wajib mengecek obat yang diterima, mulai dari kemasan, jenis, jumlah obat, bentuk sediaan obat, dan dilihat kesesuaiannya dengan isi dokumen LPLPO (Nurniati dan Lestari, 2017). Proses penerimaan merupakan proses pertama masuknya obat ke puskesmas. Proses ini menjadi penting karena data awal terkait keberadaan obat mulai dari jumlah, tanggal kedaluwarsa, dan lain-lain harus dipastikan sesuai dengan yang diberikan oleh IFK. Keadaan dan mutu obat juga harus diperhatikan karena obat yang rusak tidak akan dapat digunakan oleh puskesmas. Proses pengecekan mulai dari jumlah, jenis, bentuk, dan seterusnya penting untuk dilakukan agar kondisi awal obat sebelum disimpan di dalam gudang dapat dipastikan sudah tepat.

\section{Proses Penyimpanan Obat}

Pada penelitian ini, diketahui bahwa keseluruhan proses penyimpanan obat telah sesuai dengan Peraturan Menteri Kesehatan Nomor 74 Tahun 2016, baik pada puskesmas dengan angka stagnant tinggi maupun pada puskesmas dengan angka stagnant rendah. Terdapat empat indikator yang dilihat dalam proses penyimpanan obat yang disesuaikan dengan Peraturan Menteri Kesehatan Nomor 74 Tahun 2016 yang terdiri pertimbangan proses penyimpanan, penyimpanan psikotropika dan narkotika, gudang terpisah dari barang yang dapat mencemari obat, dan penggunaan metode FIFO atau FEFO (Kementerian Kesehatan Republik Indonesia, 2016).

Salah satu tanggungjawab apoteker adalah harus selalu menjaga obat agar terhindar dari kerusakan, kedaluwarsa, dan hilang (Seto, Nita dan Triana, 2015). Salah satu tujuan penyimpanan obat adalah untuk memelihara obat. Penyimpanan sediaan farmasi sendiri adalah kegiatan pengaturan sediaan farmasi yang agar aman, menghindari kerusakan fisik maupun kimia, dan menjaga mutu obat agar terus terjamin (Kementerian Kesehatan Republik Indonesia, 2016).

Selanjutnya, berdasarkan hasil wawancara serta observasi gudang obat diketahui bahwa seluruh puskesmas yang menjadi sampel penelitian baik puskesmas dengan angka stagnant tinggi maupun puskesmas dengan angka stagnant rendah telah memisahkan obat golongan psikotropika dan narkotika dengan obat lainnya. Penyimpanan dilakukan pada lemari khusus yang diberi label dan dikunci. Pemegang kunci lemari khusus ini adalah penanggungjawab gudang obat.

Penyimpanan obat golongan narkotika dan psikotropika yaitu harus dipisahkan dari obat lain. Selain itu juga disimpan pada lemari khusus dan dikunci ganda (double). Gudang obat puskesmas juga sebaiknya memiliki fasilitas dan sistem penyimpanan obat yang baik. Hal ini agar mutu obat tetap terjaga juga memudahkan dalam pengontrolan dan pengendalian obat. Penyimpanan dan pendistribusian obat juga sebaiknya menggunakan prinsip First In First Out (FIFO) dan First Expired First Out (FEFO), hal ini untuk mengurangi kemungkinan obat kedaluwarsa (Soeprijanto, Hapsari dan Utaminingrum, 2016).

Selain itu dari hasil wawancara diketahui bahwa terkait penggunaan metode penyimpanan, seluruh puskesmas menggunakan metode FIFO atau FEFO maupun penggabungan keduanya. Selain itu, penyimpanan dengan alfabetis juga digunakan di beberapa puskesmas. Penggunaan sistem FIFO dan FEFO dalam menata obat di gudang akan menjamin kualitas pengelolaan obat menjadi lebih efisien (Mahalia, 2017). 


\section{Proses Pendistribusian Obat}

Pada penelitian ini, diketahui bahwa proses pendistribusian obat telah sesuai dengan Peraturan Menteri Kesehatan Nomor 74 Tahun 2016, baik pada puskesmas dengan angka stagnant tinggi maupun pada puskesmas dengan angka stagnant rendah. Terdapat empat indikator yang dilihat dalam proses pendistribusian obat yang disesuaikan dengan Peraturan Menteri Kesehatan Nomor 74 Tahun 2016 terdiri keterlibatan tenaga kesehatan lain, adanya bukti pengeluaran obat, terdapat jadwal pendistribusian, dan terdapat penentuan floor stock (Kementerian Kesehatan Republik Indonesia, 2016).

Terkait indikator keterlibatan tenaga kesehatan pada proses pendistribusian obat diketahui bahwa seluruh puskesmas telah sesuai dengan Peraturan Menteri Kesehatan Nomor 74 Tahun 2016. Selanjutnya pada indikator adanya bukti pengeluaran obat juga diketahui bahwa seluruh puskesmas telah sesuai dengan Peraturan Menteri Kesehatan Nomor 74 Tahun 2016. Selanjutnya untuk indikator penentuan floor stock seluruh puskesmas juga telah sesuai dengan Peraturan Menteri Kesehatan Nomor 74 Tahun 2016.

Pada penelitian ini diketahui bahwa 1 puskesmas (20\%) dengan angka stagnant tinggi tidak memiliki jadwal pendistribusian obat yang dilakukan ke jaringan puskesmas. Selanjutnya 2 puskesmas (40\%) dengan angka stagnant rendah juga tidak memiliki jadwal pendistribusian obat ke jaringan puskesmas. Dari keseluruhan puskesmas masih terdapat beberapa puskesmas yang tidak memiliki jadwal pendistribusian ke jaringan puskesmas. Berdasarkan hasil wawancara yang dilakukan jadwal pendistribusian yang ada sebagian besar setiap tiga bulan sekali kemudian beberapa puskesmas juga memiliki jadwal pendistribusian setiap satu bulan sekali. puskesmas yang tidak memiliki jadwal pendistribusian tetap menjawab bahwa adanya jadwal pendistribusian tidak selalu dipatuhi oleh pengelola obat di jaringan puskesmas. Hal ini membuat pengambilan obat tidak selalu terjadwal dan puskesmas mengikuti jaringan puskesmas di bawahnya.

Obat yang didistribusikan harus dicatat pada buku pengeluaran barang dan formulir bukti pengeluaran obat. Pada formulir pengeluaran obat berisi catatan penerimaan, pemeriksaan obat, juga pengiriman obat oleh sub unit. Pendistribusian obat ke sub unit sebaiknya dilakukan secara rutin setiap bulan agar sub unit dapat memperoleh obat sesuai kebutuhannya (Soeprijanto, Hapsari dan Utaminingrum, 2016). Waktu pendistribusian yang tidak tepat dapat mencerminkan kurang terpadunya perencanaan pengelolaan obat yang ada (Waluyo, Athiyah dan Nurul Rochmah, 2014).

Penelitian lain yang dilakukan oleh Agus Sulistyorini (2016) diketahui bahwa hanya 52,63\% UPTD puskesmas tempat dia meneliti yang memiliki rencana jadwal distribusi ke unit-unit layanan. Alasan tidak adanya rencana jadwal distribusi obat ke unit layanan adalah petugas dari unit layanan melakukan permintaan obat dengan menggunakan LPLPO yang ditulis pada kolom permintaan ketika stok mulai menipis dan biasanya dilakukan sebulan sekali. Tidak adanya jadwal distribusi obat akan menyulitkan petugas dalam mengendalikan persediaan.

\section{Proses Pencatatan, Pelaporan, dan Pengarsipan Obat}

Pada penelitian ini, diketahui bahwa pada proses pencatatan, pelaporan, dan pengarsipan obat seluruh puskesmas dengan angka stagnant rendah telah sesuai dengan Peraturan Menteri Kesehatan Nomor 74 Tahun 2016 sedangkan, puskesmas dengan angka stagnant tinggi sebanyak 1 puskesmas (20\%) belum sesuai dengan Peraturan Menteri Kesehatan Nomor 74 Tahun 2016. Terdapat dua indikator yang dilihat dalam proses pencatatan, pelaporan, dan pengarsipan obat yang disesuaikan dengan Peraturan Menteri Kesehatan Nomor 74 Tahun 2016 yang terdiri keterlibatan tenaga kesehatan lain dan kelengkapan dokumen obat (Kementerian Kesehatan Republik Indonesia, 2016).

Terkait indikator keterlibatan tenaga kesehatan sebanyak 6 puskesmas (60\%) dari keseluruhan puskesmas telah sesuai dengan Peraturan Menteri Kesehatan Nomor 74 Tahun 2016. Selanjutnya terkait indikator kelengkapan dokumen sebanyak 4 puskesmas $(80 \%)$ dengan angka stagnant rendah telah sesuai dengan Peraturan Menteri Kesehatan Nomor 74 Tahun 2016. Kemudian diikuti dengan 3 puskesmas (60\%) dengan angka stagnant tinggi tidak sesuai dengan Peraturan Menteri Kesehatan Nomor 74 Tahun 2016. Diketahui dari hasil wawancara dan studi dokumen yang dilakukan bahwa terkait ketersediaan kartu stok, seluruh puskesmas telah memiliki kartu stok obat, namun hanya 2 puskesmas (20\%) dari keseluruhan puskesmas yang melakukan pengisian kartu stok secara rutin setiap ada pengeluaran obat. Selain itu, terkait buku harian pengeluaran dan penerimaan obat, hanya 3 puskesmas (30\%) dari keseluruhan puskesmas yang memiliki buku harian pengeluaran dan penerimaan obat.

Penelitian lain yang dilakukan oleh Nurniati \& Lestari (2017) menjelaskan bahwa kegiatan pencatatan di puskesmas tempat dia meneliti yaitu meliputi obat yang telah diterima, disimpan, didistribusikan, digunakan di puskesmas dan atau unit lainnya. Pencatatan stok obat dilakukan pada kartu stok dan LPLPO. Pencatatan dilakukan agar jumlah obat ada di tempat penyimpanan selalu terkontrol. Selain itu dalam penelitian yang dilakukan oleh Satrianegera et al., (2018) diketahui bahwa di instansi tempat dia melakukan penelitian juga dilakukan pencatatan secara rutin terkait obat masuk dan obat keluar untuk mengendalikan sediaan yang ada. 
Apabila tidak terdapat kartu stok puskesmasakan sulit memantau stok obat dan membuat perencanaan secara riil. Data yang tidak akurat bisa mengakibatkan perencanaan menjadi tidak akurat. Hal ini juga akan mempersulit untuk menemukan permasalahan yang sebenarnya terjadi di puskesmas. Tersedianya data pencatatan obat dapat meningkatan keakuratan pengeloloaan obat (Waluyo, Athiyah dan Nurul Rochmah, 2014).

\section{Proses Pemantauan dan Evaluasi Obat}

Pada penelitian ini, diketahui bahwa pelaksaan proses pemantauan dan evaluasi obat di keseluruhan puskesmas baik puskesmas dengan angka stagnant tinggi maupun puskesmas dengan angka stagnant rendah belum sesuai dengan Peraturan Menteri Kesehatan Nomor 74 Tahun 2016. Terdapat tiga indikator yang dilihat dalam proses pemantauan dan evaluasi obat yang disesuaikan dengan Peraturan Menteri Kesehatan Nomor 74 Tahun 2016 yaitu melakukan pemantauan dan evaluasi manajemen logistik secara berkala, terdapat jadwal pelaksanaan pemantauan dan evaluasi, serta yang terakhir adalah adanya bukti terkait proses pelaksanaan pemantauan dan evaluasi (Kementerian Kesehatan Republik Indonesia, 2016).

Pemantauan merupakan pengamatan perkembangan pelaksanaan perencanaan obat, mengidentifikasi, dan mengantisipasi permasalahan yang akan timbul agar dapat diambil tindakan sedini mungkin. Selanjutnya, evaluasi merupakan serangkaian prosedur untuk menilai dan mendapatkan informasi tentang keberhasilan pencapaian tujuan kegiatan, hasil, dan dampaknya (Direktorat Tata Kelola Obat Publik dan Perbekalan Kesehatan, 2010). Evaluasi berfokus pada apa yang diharapkan akan dicapai, memeriksa rantai hasil, proses, faktor kontekstual, dan kausalitas, untuk memahami pencapaian atau kekurangannya (World Health Organization, 2013).

Pada penelitian ini diketahui bahwa puskesmas dengan angka stagnant tinggi dan puskesmas dengan angka stagnant rendah telah melakukan kegiatan pemantauan dan evaluasi secara periodik. Namun, seluruh puskesmas tidak memiliki jadwal pemantauan dan evaluasi yang dilakukan secara periodik. Kemudian terkait bukti atau hasil kegiatan pemantauan dan evaluasi juga tidak ada puskesmas yang memiliki bukti terkait kegiatan pemantauan dan evaluasi yang dilakukan. Pada saat penelitian seluruh puskesmas menyatakan bahwa telah dilakukan kegiatan pemantauan dan evaluasi terkait manajemen logistik obat namun kegiatan ini tidak bersifat formal seperti kegiatan pemantauan dan evaluasi pada kegiatan atau program lainnya yang ada di puskesmas. Oleh karena itu, tidak ada jadwal tetap dan bukti baik itu bukti foto atau dokumen.

Pada penelitian yang dilakukan oleh Elldy (2014) diketahui bahwa Kepala Instalasi Farmasi melakukan kegiatan pemantauan terhadap bagian logistik dengan melakukan evaluasi setiap satu bulan sekali setelah selesai melakukan stok opname untuk melihat kemungkinan risiko yang dapat timbul. Inspeksi langsung yang jarang dilakukan dapat menimbulkan kurangnya kesadaran karyawan akan masalah-masalah kecil yang terjadi di dalam gudang. Untuk itu kepala instansi dan koordinator logistik perlu memaksimalkan kegiatan inspeksi berkala secara terpisah ke dalam gudang agar karyawan dapat menjalankan tugasnya dengan maksimal serta memantau risiko yang mungkin terjadi agar dapat segera memikirkan rekomendasi perbaikan yang sesuai.

Di sisi lain, berdasarkan penelitian yang dilakukan oleh Melinda, Dewi S, \& Hutapea R, (2019) apabila apoteker yang bertanggungjawab tidak melakukan evaluasi, perencanaan obat dapat menjadi tidak tepat jenis, jumlah, juga menjadi tidak tepat waktu. Hal ini dapat mengakibatkan terjadinya stok berlebih dan kekosongan obat. Apoteker yang tidak melakukan supervisi pada stok di unit, pemakaian sehari-hari, dan tidak dilakukannya evaluasi perencanaan dapat mengakibatkan terjadinya obat stagnant. Hasil evaluasi rutin dapat menjadi pertimbangan utama untuk perbaikan manajemen persediaan obat pada tahun berikutnya. Salah satu upaya perbaikan manjemen logistik obat adalah mengadakan evaluasi mutu, perencanaan, dan kebutuhan unit. Hal ini juga memperhatikan bahwa evaluasi harus diikuti dengan tindakan kedepannya agar ada perbaikan (Mellen Cuyno dan J.Pudjirahardjo, 2013).

\section{KESIMPULAN}

Berdasarkan hasil penelitian dan pembahasan peneliti dapat menyimpulkan bahwa pada keseluruhan proses manajemen logistik obat di UPTD puskesmas Kabupaten Sampang terdapat beberapa proses yang telah sesuai dengan Peraturan Menteri Kesehatan Nomor 74 Tahun 2016 yaitu proses perencanaan obat, proses permintaan obat, proses penerimaan obat, proses penyimpanan obat, dan proses pendistribusian obat. Selanjutnya untuk proses pencatatan, pelaporan, dan pengarsipan obat, pada puskesmas dengan angka stagnant rendah, seluruh puskesmas telah sesuai dengan Peraturan Menteri Kesehatan Nomor 74 Tahun 2016, sedangkan pada puskesmas dengan angka stagnant tinggi masih terdapat 1 puskesmas (20\%) yang belum sesuai dengan Peraturan Menteri Kesehatan Nomor 74 Tahun 2016. Kemudian terkait proses pemantauan dan evaluasi obat, seluruh puskesmas belum sesuai dengan Peraturan Menteri Kesehatan Nomor 74 Tahun 2016

Saran yang dapat diberikan kepada puskesmas adalah sebaiknya perencanaan obat juga mempertimbangkan data mutasi obat dan sisa persediaan obat dari periode sebelumnya. Pada saat menerima obat dari Instalasi Farmasi Kabupaten, sebaiknya puskesmas melakukan pengecekan menyeluruh sebelum obat dimasukkan ke dalam gudang. Pengecekan yang dilakukan mulai dari mengecek bentuk dan jenis obat, dokumen 
yang menyertai obat, jumlah obat, jumlah kemasan/peti, dan tanggal kedaluwarsa obat. Selanjutnya, puskesmas sebaiknya membuat jadwal distribusi yang tetap dan jelas ke jaringan puskesmas (Polindes, Pustu, dan Ponkesdes) seperti setiap bulan, setiap tiga bulan, dan seterusnya bergantung kebutuhan dan kesepakatan dengan jaringan puskesmas. Penanggung jawab obat sebaiknya mengisi kartu stok serta buku harian penerimaan dan pengeluaran obat dengan teratur setiap terjadi penerimaan dan pengeluaran obat ke gudang puskesmas. puskesmas juga sebaiknya melakukan pemantauan dan evaluasi manajemen logistik secara berkala seperti setiap tiga bulan atau setiap enam bulan agar dapat dilakukan tindakan segera apabila terdapat hal yang tidak sesuai dengan rencana awal.

\section{ACKNOWLEDGEMENT}

Terima kasih khususnya kepada Bapak Djazuly Chalidyanto atas seluruh bantuan dan masukannya untuk memperbaiki kekurangan dalam penulisan artikel. Kemudian terima kasih kepada bapak dan ibu petugas pengelola gudang obat di Puskesmas yang telah bersedia menjadi responden dan mau bekerja sama untuk memberikan data dan informasi yang saya butuhkan sehingga artikel ini bisa tersusun dengan data yang lengkap.

\section{REFERENSI}

Abadi, M. (2015) Analisis Dasar Hukum, Kebijakan, Dan Peraturan Penanganan Obat Overstock Di UPT Farmasi Dan Alat Kesehatan Kota Yogyakarta. Universitas Gadjah Mada.

Dinas Kesehatan Kabupaten Sampang (2019) Laporan Pemakaian Dan Lembar Permintaan Obat (LPLPO) Puskesmas Kabupaten Sampang Januari-Oktober 2019.

Direktorat Tata Kelola Obat Publik Dan Perbekalan Kesehatan (2010) Materi Pelatihan Manajemen Kefarmasian Di Puskesmas. Jakarta: Jakarta Japan International Cooperation Agency (Jica).

Elldy, G. (2014) Audit Kepatuhan Bagian Logistik Instalasi Farmasi (Studi Kasus Pada Rsup Dr. Kariadi Semarang). Universitas Kristen Satya Wacana.

Erlin, K. (2017) Analisis Manajemen Logistik Obat Di Instalasi Farmasi Rumah Sakit Islam Siti Aisyah Madiun Tahun 2017. Stikes Bhakti Husada Mulia Madiun.

Kementerian Kesehatan Republik Indonesia (2016) 'Peraturan Menteri Kesehatan Republik Indonesia Nomor 74 Tahun 2016 Tentang Standar Pelayanan Kefarmasian Di Puskesmas', (June).

Kementrian Kesehatan Republik Indonesia (2019) Laporan Kinerja Direktorat Pelayanan Kefarmasian Tahun 2018 | Direktorat Jenderal Kefarmasian Dan Alat Kesehatan. Jakarta.

Kementrian Kesehatan Republik Indonesia (2020) Laporan Kinerja Direktorat Pelayanan Kefarmasian Tahun 2019 | Direktorat Jenderal Kefarmasian Dan Alat Kesehatan. Jakarta.

Mahalia, L. D. (2017) 'Analisis Penyimpanan Dan Distribusi Alat Dan Obat Kontrasepsi Pemerintah Di Kota Palangkaraya', Jurnal Forum Kesehatan, 7(2), Pp. 56-64.

Melinda, Dewi S, \& Hutapea R, F. (2019) 'Evaluasi Peran Apoteker Dalam Meningkatkan Mutu Pelayanan Kefarmasian Dan Penggunaan Obat Di Rs Kartika Husada', Manajemen Dan Administrasi Rumah Sakit Indonesia (Marsi) Volume 3 No 2 Oktober 2019., 3(2), Pp. 102-112.

Mellen Cuyno, R. dan J.Pudjirahardjo, W. (2013) 'Drugs Stockout And Stagnant Determinants And Loss In Logistic Unit Of Haji General Hospital Surabaya', Jurnal Administrasi Kesehatan Indonesia, 1.

Nopiyansyah, N., Purba, A. V. dan Hidayat, W. U. (2020) 'Evaluasi Manajemen Pengadaan Dan Distribusi Obat Di Dinas Kesehatan Kota Bandar Lampung Periode Tahun 2016’, Holistik Jurnal Kesehatan, 14(1), Pp. 118-128. Doi: 10.33024/Hjk.V14i1.2088.

Nurniati, L. dan Lestari, H. (2017) 'Studi Tentang Pengelolaan Obat Di Puskesmas Buranga Kabupaten Wakatobi Tahun 2016', (Jurnal Ilmiah Mahasiswa Kesehatan Masyarakat), 1(3). Doi: 10.37887/Jimkesmas.V1i3.1254.

Sardjoko, S. Et Al. (2018) Penguatan Pelayanan Kesehatan Dasar Di Puskesmas. Jakarta: Direktorat Kesehatan Daan Gizi Masyarakat, Kedeputian Pembangunan Manusia, Masyarakat Dan Kebudayaan, Kementerian Ppn/Bappenas.

Satrianegera, F. Et Al. (2018) 'Gambaran Pengelolaan Persediaan Obat Di Gudang Farmasi Rsud Syekh Yusuf Gowa', Al-Sihah: The Public Health Science Journal, 10(2), Pp. 180-191. Doi: 10.24252/As.V10i2.6887.

Seto, S., Nita, Y. dan Triana, L. (2015) Manajemen Farmasi 2: Edisi 4 : Lingkup Apotek, Farmasi Rumah Sakit, Industri, Pedagang Besar Farmasi. 4th Edn. Surabaya: Airlangga University Press.

Soeprijanto, R. A., Hapsari, I. dan Utaminingrum, W. (2016) 'Evaluasi Manajemen Pengelolaan Obat Di Puskesmas Rawat Inap Kabupaten Purbalingga Berdasarkan Tiga Besar Alokasi Dana Pengadaan Obat', Pharmacy: Jurnal Farmasi Indonesia (Pharmaceutical Journal Of Indonesia), 8(03). Doi: 10.30595/Pji.V8i03.1126.

Sulistyorini, A. (2016) Pengelolaan Ketersediaan Obat Di UPTD Puskesmas Kabupaten Kediri. 
Waluyo, Y., Athiyah, U. dan Nurul Rochmah, T. (2014) 'Analisis Faktor Yang Mempengaruhi Pengelolaan Obat Publik Di Instalasi Farmasi Kabupaten (Studi Di Papua Wilayah Selatan) District Pharmacy Installation (Study In Southern Papua Area))', Jurnal Ilmu Kefarmasian Indonesia, 13(1), Pp. 94-101.

World Health Organization (2013) WHO Evaluation Practice Handbook. Switzerland: WHO Press. 